\title{
Animal models of epilepsy: use and limitations
}

\author{
This article was published in the following Dove Press journal: \\ Neuropsychiatric Disease and Treatment \\ 9 September 2014 \\ Number of times this article has been viewed
}

\section{Ludmyla Kandratavicius' \\ Priscila Alves Balista' \\ Cleiton Lopes-Aguiar' \\ Rafael Naime Ruggiero' \\ Eduardo Henrique Umeoka ${ }^{2}$ \\ Norberto Garcia-Cairasco ${ }^{2}$ \\ Lezio Soares Bueno-Junior' \\ Joao Pereira Leite'}

'Department of Neurosciences and Behavior, ${ }^{2}$ Department of Physiology, Ribeirao Preto School of Medicine, University of Sao Paulo, Ribeirao Preto, Brazil
Correspondence: Ludmyla Kandratavicius Department of Neurosciences and Behavior, Ribeirao Preto School of Medicine, University of Sao Paulo, Av Bandeirantes 3900, CEP I4049-900,

Ribeirao Preto, SP, Brazil

Tel +55 I6 36022796

Fax +55 I6 36330866

Email ludykandra@gmail.com

\begin{abstract}
Epilepsy is a chronic neurological condition characterized by recurrent seizures that affects millions of people worldwide. Comprehension of the complex mechanisms underlying epileptogenesis and seizure generation in temporal lobe epilepsy and other forms of epilepsy cannot be fully acquired in clinical studies with humans. As a result, the use of appropriate animal models is essential. Some of these models replicate the natural history of symptomatic focal epilepsy with an initial epileptogenic insult, which is followed by an apparent latent period and by a subsequent period of chronic spontaneous seizures. Seizures are a combination of electrical and behavioral events that are able to induce chemical, molecular, and anatomic alterations. In this review, we summarize the most frequently used models of chronic epilepsy and models of acute seizures induced by chemoconvulsants, traumatic brain injury, and electrical or sound stimuli. Genetic models of absence seizures and models of seizures and status epilepticus in the immature brain were also examined. Major uses and limitations were highlighted, and neuropathological, behavioral, and neurophysiological similarities and differences between the model and the human equivalent were considered. The quest for seizure mechanisms can provide insights into overall brain functions and consciousness, and animal models of epilepsy will continue to promote the progress of both epilepsy and neurophysiology research.
\end{abstract}

Keywords: epilepsy, animal model, pilocarpine, kindling, neurodevelopment

\section{Introduction}

Temporal lobe epilepsy (TLE) is the most common form of epilepsy in humans, in which seizures spread to neighboring cortices and hippocampal neuron loss and other neuropathological changes may take place. ${ }^{1,2}$ Comprehension of complex mechanisms underlying epileptogenesis and seizure generation in TLE and other forms of epilepsy cannot be fully acquired in clinical studies with humans. As a result, the use of appropriate animal models is essential. In the present review, we summarize some of the most frequently used rodent animal models of TLE and other epileptic disorders, highlighting induction methods and manifestations as well as major uses and limitations.

\section{Chemoconvulsants}

Rodents with spontaneous recurrent seizures have been generated by using chemoconvulsants, primarily pilocarpine and kainic acid. ${ }^{3}$ Usually, these models intend to mimic TLE, and therefore rodents must display a similar "clinical history" as the human counterpart, including an initial precipitant injury afflicting the hippocampus and/or the temporal lobe (eg, status epilepticus [SE]), a latent period between the injury and the occurrence of spontaneous seizures, chronic manifestation of spontaneous seizures (usually partial and tonic-clonic seizures), and histopathological changes deemed characteristic of TLE. ${ }^{2,4,5}$ Unfortunately, animal models of chronic epilepsy are not widely used because of time constraints and costs. 
Kainic acid was one of the first compounds used to model TLE in rodents. ${ }^{6}$ It is an L-glutamate analog, the systemic or intracerebral administration of which causes neuronal depolarization and seizures, preferentially targeting the hippocampus. ${ }^{7}$ Injected rodents show recurrent seizures, usually secondarily generalized and of variable frequency, with remarkable histopathological correlates of hippocampal sclerosis. ${ }^{8}$ Kainic acid has the advantage of causing habitually hippocampus-restricted injuries, unlike pilocarpine, which can also produce lesions in neocortical areas. ${ }^{6}$ Nevertheless, extrahippocampal areas are also significantly compromised in human TLE, ${ }^{9}$ making pilocarpine another useful chemoconvulsant.

Pilocarpine is a muscarinic acetylcholine receptor agonist. Systemic or intracerebral injection of pilocarpine causes seizures that build up into a limbic SE. ${ }^{10,11}$ Structural damages and subsequent development of spontaneous recurrent seizures resemble those of human complex partial seizures. ${ }^{12}$ In fact, antiepileptic drugs (AEDs) that are effective against complex partial seizures in humans can also halt spontaneous seizures in the pilocarpine model. ${ }^{13}$ In addition, there are several network and neurochemical similarities between human TLE and the pilocarpine model. For instance, the subiculum can generate interictal activity in both the human $\mathrm{TLE}^{14}$ and the pilocarpine model. ${ }^{15}$ Neurotrophins are upregulated in the hippocampus of mesial TLE patients, ${ }^{16}$ as well as in the hippocampus and neocortex of pilocarpine-treated rats. ${ }^{17}$ Cognitive and memory deficits commonly found in TLE patients ${ }^{18,19}$ are also present in pilocarpine-injected rats. ${ }^{20,21}$

Other compounds such as pentylenetetrazol (PTZ), strychnine, N-methyl-D,L-aspartate, tetanus toxin, and penicillin are widely used as acute seizure models, and not as animal models of epilepsy. The difference is that seizure models may be useful for rapid screening of AED action, but they do not necessarily result in chronic epilepsy, with the exception of tetanus toxin, ${ }^{22}$ and probably of repeated penicillin injections. ${ }^{23}$ Crude extract of the star fruit and its active compound caramboxin are also potent chemoconvulsants and are capable of inducing $\mathrm{SE},{ }^{24}$ but it remains to be described whether they also result in later spontaneous recurrent seizures, as in chronic models. Compounds that trigger seizures can be used on testing different AEDs that would act on different seizure types. For instance, strychnine and $\mathrm{N}$-methyl-D,L-aspartate produce generalized tonic-clonic seizures, as well as PTZ nonconvulsive absence or myoclonic seizures.$^{25}$ Ethosuximide, trimethadione, valproate, and other clinically efficacious drugs have been discovered by using seizure models. ${ }^{26}$ However, drugs such as levetiracetam, vigabatrin, and tiagabine, which act on mechanisms other than sodium channel blockade, were discovered in models that predict drug efficacy against partial seizures ${ }^{27}$ (eg, those seen in chronic TLE models or full electrical kindling).

In summary, face validity (the extent to which the animal model reproduces the symptoms and phenotypes associated with the human disease) of chemoconvulsants that result in chronic epilepsy is relatively high, as they reproduce most of neuropathological findings, as well as the behavioral, cognitive, and psychiatric symptoms of TLE. However, none of these models are completely clinically validated, as they are not predictive of clinical response to all therapeutic strategies. The choice of a given model should, therefore, rely on which group of specific features one is aiming to study.

\section{Chemoconvulsants in the immature brain}

SE has a special propensity to develop in the immature brain, with about $50 \%$ of the cases occurring in children younger than 2 years old. ${ }^{5,28}$ Clinical studies point out that $13 \%-74 \%$ of children who suffered a convulsive SE developed epilepsy. ${ }^{29}$ Furthermore, SE during development is often associated with hippocampal injury and mesial temporal sclerosis, as well neurological, cognitive, and behavioral impairments. Thus, animal models of SE are important for investigating whether SE can result in maladaptive neuronal reorganization, epileptogenesis, and cognitive impairment. ${ }^{30}$

$\mathrm{SE}$ in the developing brain is modeled in immature rodents (younger than 21 postnatal days $[<\mathrm{P} 21]$ ) mainly by kainic acid and pilocarpine administration. Administration protocol is similar to that used in adult rodents, except that young ones have enhanced susceptibility to seizure induction, thus requiring smaller doses. ${ }^{31,32}$ In both models, seizure manifestation becomes more evident with age progression. ${ }^{31}$ In addition, kainic acid excitotoxicity is higher in older animals, ${ }^{33}$ as are severity and duration of SE. ${ }^{30}$ In rats older than P7, SE induced by pilocarpine or kainic acid ceases exploratory activity, and animals develop scratching, body tremors, chewing, clonic movements of the forelimbs, and head bobbing before progressing into tonic and clonic activity. ${ }^{30}$

Rodents submitted to SE during development show minimal or no detectable cellular damage in adulthood. ${ }^{34,35}$ However, studies on the acute and short-term effects of SE indicate neuronal injury in the hippocampus, amygdala, and mediodorsal nucleus of thalamus. ${ }^{36,37}$ Mossy fiber sprouting is also present in immature SE models using kainic acid and pilocarpine, although young rats do not exhibit the prominent reorganization that is typically observed in the adult ones. ${ }^{34,35}$ 
Recently, Kubová and Mareš $\breve{3}^{38}$ showed that pilocarpine induction of SE at P12 and P25 led to cognitive impairments and that the magnitude of such impairments increased with age. Interestingly, cognitive deficits correlated with the severity of tissue damage, but not with seizure parameters.

Multiple administrations of PTZ or flurothyl are also used to mimic recurrent generalized tonic-clonic seizures in immature rodents. ${ }^{32}$ Flurothyl is a volatile, fast-acting central nervous system stimulant that causes seizures with myoclonic jerks followed by forelimb clonus, wild running, loss of posture, and severe tonic posturing. ${ }^{32}$ Recovery is very fast, and the animals exhibit normal behavior within 30 minutes. Seizures are commonly induced five times a day over the course of 5-10 days (usually P0-P9) with intervals of at least 2 hours. ${ }^{39}$ In the PTZ model, seizures are commonly induced by a single systemic administration, and PTZ can even induce SE if given in a sufficient amount. ${ }^{32,40}$ Seizurerelated behaviors are also age-dependent. Compared with P18, P28, and adult rats, P10 animals injected with PTZ have shorter latency to generalized tonic-clonic seizures. ${ }^{41}$

No evident neuron loss is seen in rodents submitted to flurothyl or PTZ recurrent seizures during development. ${ }^{42-44}$ However, mossy fiber sprouting occurs in adult animals. ${ }^{39,40,43}$ Extratemporal areas can also be affected, including increased prefrontal cortex thickness, synaptic plasticity alterations, and decreased behavioral flexibility. ${ }^{45,46}$ These data indicate substantial changes in prefrontal cortex function, which may be an important substrate of cognitive deficits in humans with a history of infant or juvenile seizures. ${ }^{45}$ Rodents submitted to early-life flurothyl recurrent seizures present with increased seizure susceptibility when they are adults. ${ }^{39,42}$ However, as a limitation of this model, adult animals do not present with spontaneous seizures.

\section{Electrical stimulation}

Animal models of seizures induced by electrical stimulation convey the advantage of reproducing epileptogenic features in the intact brain with low mortality and high reproducibility. Moreover, unlike chemical-induced seizures, postictal alterations from electrical stimulation can be investigated when the epileptogenic cause is no longer present. However, seizure modeling by electrical stimulation does not provide cell-type specificity in the brain. In addition, stimulation protocols can be costly and laborious when used for chronic studies. ${ }^{32}$

\section{Electroshock-induced seizures}

Electroshock-induced seizures (ES) are among the most studied models of electrical stimulation. Electroshock is conveniently applied a single time and does not require the stereotaxic implant of electrodes. It involves whole-brain stimulation protocols (eg, $6 \mathrm{~Hz}$ in mice and $50-60 \mathrm{~Hz}$ in rats) and may be divided into minimal ES and maximal ES. Minimal ES are a putative model of myoclonic seizures and can be induced with current stimulation through corneal electrodes. In this case, the epileptiform activity is usually more prominent in the forebrain and is associated with minimal clonic behavioral seizures. ${ }^{47}$ Minimal ES may become generalized if stimulation intensity is increased. ${ }^{48}$ In turn, maximal ES induction has been useful when modeling generalized tonic-clonic seizures. It is mostly associated with hindbrain seizures and can be generated by auricular stimulation at threshold current intensities. ${ }^{49}$ Maximal ES and PTZ seizure models have been largely employed for AED screening. However, AEDs that protect against partial and nonconvulsive seizures in epileptic patients failed to do so in the maximal ES and PTZ models, respectively. ${ }^{26}$ Therefore, a battery of models is required during the development of AEDs. ES models have also been employed to examine modifications of intracellular cascades and/or posttranslational modifications of proteins to clarify how epileptiform activities relate to synaptic plasticity dysfunctions, cognitive deficits, and psychiatric comorbidities. ${ }^{50-52}$ For instance, Tsankova et $\mathrm{al}^{51}$ demonstrated that chromatin remodeling is involved in ES-induced regulation of c-fos and the brainderived neurotrophic factor (BDNF).

\section{Afterdischarges}

The single-evoked epileptic afterdischarges model (AD) is another important approach to electrical stimulation. It is induced in specific brain regions, resembling complex partial seizures if applied into limbic structures and myoclonic seizures if applied into the sensorimotor cortex. AD is useful for investigating electrophysiological and behavioral correlates of focally generated seizure-like patterns that often spread to nonstimulated networks. ${ }^{53,54}$ Electrographic properties of AD largely depend on the brain region stimulated. For instance, spike-and-wave patterns can be elicited by AD induction either in the neocortex or mediodorsal thalamus. In contrast, $\mathrm{AD}$ induction in limbic circuits produces fast spikes, large delta waves, and/or sharp theta waves. ${ }^{55,56}$ The most common target for electrically induced $\mathrm{AD}$ is the hippocampus. ${ }^{56,57}$ Once hippocampal AD ends, postictal refractoriness, which precludes subsequent seizures, is often observed. ${ }^{54}$ This period is followed by a pattern of low-amplitude and fast oscillations (40-80 Hz), also defined as the AD termination oscillation. ${ }^{58}$ Behavioral alterations induced by hippocampal 
$\mathrm{AD}$ include freezing during stimulus, wet dog shake at the end or just after the stimulus, and hyperlocomotion and stereotypies (eg, excessive grooming, rearing, and/or head movements), along with the AD termination oscillations. ${ }^{54,57}$ Some authors claim that $\mathrm{AD}$ experiments can probe underlying mechanisms of the relationship between psychosis and epilepsy (eg, postictal psychosis). ${ }^{59,60}$ In fact, it has been reported that hippocampal AD induction enhances gamma oscillations in the nucleus accumbens and medial prefrontal cortex and that such an effect is associated with hyperlocomotion and stereotypies. ${ }^{55,59,61,62}$ These alterations can be reversed by treatment with the typical antipsychotic haloperidol. ${ }^{61}$ As a consequence, hippocampal AD produces sensorimotor gating deficits, measured by prepulse inhibition of the acoustic startle 2 minutes after electrical stimulation. ${ }^{60,61}$ To date, Osawa et $\mathrm{l}^{163}$ were the first group to report the benefit of using optogenetics ${ }^{64}$ to probe hippocampal AD. The authors were able to overcome some technical limitations of the electrical stimulation; namely, the inability to manipulate the activity of specific groups of neurons and the unfeasibility of studying the spatial-temporal dynamics of neuronal activity during stimulation because of contamination of the electrophysiological recordings by electrical artifacts. ${ }^{63} \mathrm{In}$ addition to developing an electrical artifact-free model of $\mathrm{AD}$, the authors provide further understanding of the generation and termination of seizure-like activity in the septo-temporal axis of the hippocampus.

\section{Kindling}

At this time, kindling is the most studied model of electrical stimulation. Kindling refers to a seizure-induced plasticity phenomenon that occurs when repeated AD induction by electrical stimulation in a specific brain region evokes a progressive enhancement of seizure susceptibility. Ultimately, it culminates in emergence of spontaneous seizures and the establishment of a permanent epileptic state ${ }^{65}$ Initially, behavioral alterations during ADs resemble partial seizures (classes 1-3) ${ }^{66}$ which evolve into secondary generalization (classes 4-5) ${ }^{67}$ Although a fully kindled state is established after $90-100$ class 5 seizures,${ }^{68}$ it is also possible to induce spontaneous behavioral seizures and focal hippocampal injury by milder protocols, as demonstrated by the continuous perforant pathway stimulation protocol. ${ }^{69}$ Because kindling produces a fairly robust and reproducible sequence of molecular and cellular alterations in neural circuits, it has been considered a potent tool for probing epileptogenesis mechanisms..$^{70,71}$ In this sense, there is a body of evidence suggesting that kindling is not merely a chronic model of epilepsy but, rather, a relevant neurobiological phenomenon for understanding the consequences of poorly controlled seizures. ${ }^{70,72}$ Unfortunately, kindling is a costly and timeconsuming procedure comprising long periods of handling and stimulation procedures, not to mention the risk of losing or damaging the chronic implants..$^{32}$ These technical limitations might explain the lack of studies on the chronic stage of spontaneous seizures induced by kindling.

Regarding chronic models of epilepsy, it is noteworthy that limbic kindling features are distinguished from models of TLE induced by kainic acid or pilocarpine, which are initiated by severe SE associated to prominent temporal and extratemporal damage, in addition to the rapid emergence of spontaneous recurrent seizures. ${ }^{70}$ Instead, kindling produces subtle but cumulative neuronal loss and a number of cellular alterations in brain circuits that eventually result in spontaneous seizures. ${ }^{68}$ Therefore, despite being laborious, kindling provides an opportunity to study the dynamics of epileptogenic processes that are particularly relevant to TLE..$^{70}$ Recently, Srivastava et al ${ }^{73}$ took advantage of both kindling and pharmacology approaches to develop a novel experimental model of pharmacoresistant epilepsy. The authors have demonstrated that even a single exposure to lamotrigine or carbamazepine 48 hours after kindling induction leads to a decrease in the ability of these AEDs to attenuate further evoked ADs. ${ }^{73}$ Modeling pharmacoresistant epilepsies is, indeed, critical to developing new AEDs. ${ }^{26}$ Another interesting approach is the combination of genetic engineering and electrophysiological models of seizures. For instance, two recent studies with transgenic mice have provided direct evidence that the development of kindling requires the BDNF receptor tyrosine kinase B (TrkB) activation through a specific phospholipase signaling. ${ }^{71,74}$ Although the tyrosine kinase $\mathrm{B}$ presence requirement for epileptogenesis has been evaluated mostly in kindling models, we have recently shown in human mesial TLE that increased hippocampal tyrosine kinase B expression also has a prominent role in secondary generalized seizures in addition to increased seizure frequency and poor surgical outcome. ${ }^{75}$ Taken together, these findings point out the importance of combing the kindling approach with cutting-edge tools to delimit novel targets for the prevention of epileptogenesis and the treatment of pharmacoresistant epilepsies.

\section{Brain pathology}

The developing human brain is at higher risk of developing seizures, particularly during the first month of life. ${ }^{76}$ In addition to possible insults associated with the birthing 
process, the immature brain has a predominance of excitation over inhibition, which, on the one hand, is important for synaptogenesis but, on the other hand, increases seizure susceptibility. ${ }^{77}$ Animal models of seizures in the developing brain provide a unique opportunity to study this enhanced excitability during development. The main question is whether seizures in this critical period disturb neuronal circuit development and whether such disturbances promote epileptogenesis and cognitive deficits later in life. We briefly describe two of the models most used to investigate these issues.

\section{Hyperthermic seizures}

Febrile seizures are frequent in early life, with a prevalence of $2 \%-5 \%$ in children younger than 5 years. ${ }^{78}$ Although the majority of febrile seizures do not lead to sequelae, the outcome of complex febrile seizures (defined as seizures longer than 15 minutes with focal onset and possible recurrence within 24 hours) is controversial. ${ }^{79}$ Although a small proportion of febrile seizure patients will develop epilepsy, retrospective studies of patients with refractory TLE indicate a history of febrile seizures in 20\%-60\% of cases. ${ }^{80}$ Interestingly, recent studies have shown that patients with a history of febrile seizure display a different and genetic profile when compared with those without such a history. ${ }^{2,81}$ Animal models of febrile seizure were developed to investigate whether febrile seizures per se induce neuronal damage leading to epileptogenesis, and which mechanisms generate febrile seizures. ${ }^{32}$ Usually, $\mathrm{P} 10-\mathrm{P} 12$ rodent pups have their core temperature increased to $40^{\circ} \mathrm{C}-42^{\circ} \mathrm{C}$ by hot air stream for 30 minutes, stimulating prolonged convulsions. These seizures are subtler than those evoked by chemoconvulsants but are nevertheless identifiable by sudden immobility, usually followed by facial automatism and tonic body flexion. ${ }^{32}$ Ictal electroencephalography (EEG) activity consists of spike-waves and trains of spikes with increased amplitude in the hippocampus, amygdala, and temporal cortex..$^{82,83}$ Respiratory alkalosis also seems to be a component of hyperthermic seizures, as they can be mimicked by systemic bicarbonate. Hyperthermic seizures are also abolished when alkalosis is suppressed. ${ }^{82}$

One of the main questions is whether prolonged febrile seizures trigger mesial temporal lobe sclerosis and epileptogenesis. Indeed, rodent pups submitted to febrile seizures present with spontaneous seizure in adulthood. ${ }^{84}$ In addition, they show enhanced susceptibility to kainic acid ${ }^{83}$ and enhanced long-term potentiation induction in adulthood. ${ }^{85}$
In particular, this proexcitatory condition does not involve evident neuronal loss, ${ }^{86}$ which is different from what is seen in human TLE. Another difference is that in the febrile seizure model, seizures are induced by hyperthermia and not by fever, as in the human condition, which may implicate alternative mechanisms.

\section{Neonatal hypoxia}

Hypoxic encephalopathy is the most common cause of neonatal seizure. ${ }^{87}$ These seizures can be prolonged and refractory to conventional AEDs, and common sequelae include neuromotor and neurocognitive deficits and epilepsy development. ${ }^{88}$ The hypoxia rodent model was described by Jensen et al, ${ }^{89}$ who managed to replicate the unique age-dependent neonatal susceptibility to hypoxia, refractoriness to conventional AEDs, and long-term increases of seizure susceptibility. ${ }^{32}$ In this model of global hypoxia, rat pups (P10-P12) are exposed to graded global hypoxia $\left(7 \%-4 \% \mathrm{O}_{2}\right)$ for 15 minutes in a gas chamber. Younger (P5) and adult (P60) animals do not undergo seizure in these conditions. $^{90}$

Rodents submitted to this hypoxia model develop spontaneous seizures later in life, as well as mossy fiber sprouting and long-term behavioral alterations, including social deficits, memory impairments, and aggressiveness. ${ }^{91,92}$ Despite the lack of early neuronal injury, ${ }^{93}$ hypoxia-induced seizures promote hyperexcitability immediately after seizure recovery, facilitating long-term potentiation induction and generating longer ADs. ${ }^{94}$ Increased excitability persists in the adult hippocampus, suggesting that the epileptogenic effects of hypoxia are mediated by permanent effects on excitability and plasticity within hippocampal networks. ${ }^{94}$

\section{Posttraumatic epilepsy}

Traumatic brain injury (TBI) is one of the leading etiologies for symptomatic epilepsies in adults. Indeed, posttraumatic epilepsy (PTE) corresponds to $20 \%$ of all symptomatic epilepsies and refers to the condition in which recurrent spontaneous seizures occur more than 1 week after TBI. ${ }^{95}$ A clinical history similar to what occurs in post-SE TLE takes place in post-TBI PTE (an initial precipitant injury, a latent period, and chronic manifestation of spontaneous seizures), although the exact mechanisms are still under investigation. In addition, PTE models usually present with long latent periods and low yield of epileptic animals. Given the high heterogeneity of TBI in humans, TBI animal models are also diverse (there are focal models of TBI, diffuse brain injury models, mixed models of focal and 
diffuse brain injury, combined injury models, experimental models of coma, and models of repetitive concussive injury), although none of them recapitulates completely the human syndrome..$^{96}$

One of the most used strategies to simulate PTE is the fluid percussion injury model (FPI). In this model, a single episode of severe FPI is sufficient to cause PTE, ${ }^{97,98}$ and it may progress from frontal-parietal epilepsy to mesial TLE with dual pathology, as frequently found in human PTE. ${ }^{99}$ Neuropathological correlates of mesial TLE such as mossy fiber sprouting and hippocampal neuron loss are also present in the FPI model of PTE. ${ }^{98}$ Recently, Shultz et al ${ }^{100}$ examined predictive imaging and behavioral biomarkers for PTE in the FPI model, and the most representative imaging correlate in the animals that developed PTE was found in the ipsilateral hippocampus at 1 week postinjury. However, it is unknown whether these findings are related to epileptogenic processes. Modeling PTE is laborious, and few studies have compared endophenotypes between patients and animals with PTE or have focused on testing the effects of candidate AED treatments. ${ }^{96}$ If there is a true resemblance between post-SE TLE and post-TBI TLE, such as similarities in natural history of symptomatic epilepsy, neuropathological/neurochemical findings, ${ }^{98}$ and presence of major depression as a shared risk factor, ${ }^{101,102}$ corroboration depends on further comparisons between these models. Such corroboration may result in improved treatments of PTE.

\section{Genetics}

\section{Audiogenic seizures}

Audiogenic seizures (AS) are generalized seizures provoked by high-intensity acoustic stimulation. Activation of auditory pathways is crucial for AS development, and the inferior colliculus in the auditory midbrain plays a key role in audiogenic seizure initiation, although other structures participate in AS progression. ${ }^{103,104}$

The first audiogenic seizures were observed in the early 1920s in Pavlov's laboratory. ${ }^{105}$ Since then, several audiogenic strains were created; for instance, KrushinskyMolodkina in Russia, ${ }^{106}$ Genetically Epilepsy-Prone Rat in the United States, ${ }^{107}$ P77PMC rats in China, ${ }^{108}$ Wistar Albino Glaxo/Rijwijk rats (WAG/Rij) in the Netherlands, ${ }^{109}$ Wistar Audiogenic Sensitive Rat in France, ${ }^{110}$ and Wistar Audiogenic Rat (WAR) in Brazil. ${ }^{11}$ In audiogenic susceptible animals, a single acoustic stimulus triggers a reflex seizure mimicking those seen in humans. It usually begins with wild running, which progresses to a tonic-clonic phase.
Postictal events are also frequent. Despite similarities among strains, ${ }^{105}$ behavioral features of audiogenic seizures are strain-specific.

Moreover, acoustic stimulation can be applied to those strains in a chronic intermittent protocol called audiogenic kindling. ${ }^{112}$ The audiogenic kindling protocol modifies the behavior and the EEG expression of audiogenic-induced seizures, recruiting limbic circuitries in audiogenic strains. ${ }^{113}$ In WARs, audiogenic kindling induces hippocampal neurogenesis, ${ }^{114}$ although mossy fiber sprouting and neurodegeneration were not found after more than 30 audiogenic seizures. ${ }^{114,115}$

Audiogenic models of epilepsy have been used not only for reflex epilepsy and TLE studies but also to characterize comorbidities associated with the epilepsies. For example, although the WAG/Rij strain can be used as an audiogenic seizure model, it is better known as a genetic model of absence seizures. ${ }^{116}$ Therefore, the WAG/Rij is useful to study convulsive and nonconvulsive seizures in the same animal. It has also been proposed that the WAG/Rij strain is reliable for studying the comorbidity between absence epilepsy and depression, as depressive-like symptoms are present in this strain. ${ }^{117}$ In fact, major depression is a common comorbidity in focal human epilepsies. ${ }^{118}$ Studies with WARs are increasingly reinforcing that these rats can also be used to study mood disorders of epilepsy, such as pilocarpine-treated rats. ${ }^{119}$ Behavioral experiments indicate that naive WARs show anxiety-like behaviors. ${ }^{120}$ Furthermore, WARs have morphological and functional alterations in the hypothalamic-pituitary-adrenal axis ${ }^{121}$ that seem to be related to changes in the autonomic control of the WAR's cardiovascular system. ${ }^{122}$ Because of the endogenous stress, hyperactivity of the hypothalamic-pituitary-adrenal axis, higher blood pressure, and increased sympathetic tonus, WARs might also be useful to investigate events related to sudden unexplained/unexpected death in epilepsy.

Limitations of the audiogenic seizure strains are the necessity of a trigger to evoke audiogenic seizures and the lack of spontaneous recurrent seizures. In contrast, advantages are the specific trigger (sound stimulation) and substantial characterization of behavioral, cellular, and molecular alterations in both acute and chronic (kindling) protocols. In fact, acute audiogenic seizures are good models of tonic-clonic seizures with brainstem origin. The combination of seizure predisposition, which is typical of genetically developed strains, and the possibility of chemically or electrically modulating seizures potentiates the usefulness of these models in elucidating epileptogenesis and its mechanisms. 


\section{Absence seizure models}

Generalized epilepsies ( $20 \%$ of all epilepsy cases) $)^{123}$ are idiopathic, in that seizures spontaneously arise without evident causes. Unlike those seen in the focal epilepsies, idiopathic seizures have no discrete sites of initiation, as paroxysms suddenly and bilaterally spread to multiple EEG channels before rapidly vanishing from them. ${ }^{124}$ Indeed, the etiology of idiopathic seizures is rather functional, given that pathological correlates are not as evident as in focal syndromes.

Absence seizures, especially those occurring in children and juveniles, are the prototypical form of idiopathic seizures. ${ }^{125}$ They are characterized by usually brief (5-10 seconds), nonconvulsive episodes of behavioral arrest and apparent unconsciousness, although minimal levels of awareness might be retained. ${ }^{126}$ Absence seizures produce spike-and-wave discharges (SWD; $3 \mathrm{~Hz}$ ) manifested on the normal EEG background as long as the behavioral activity remains halted. ${ }^{125,127}$ Similarities of SWD and sleep spindles, in addition to the transformation from spindles to SWD in cats injected with systemic penicillin (a GABA $\mathrm{A}_{\mathrm{A}}$ antagonist), suggest a link between absence seizures and superficial stages of sleep. ${ }^{128}$ However, such a relationship is now uncertain, as absence seizures are also frequent during wakefulness, previous hypotheses of shared GABA $A_{A}$-dependent mechanisms are no longer supported, and SWD generation depends on thalamo-cortico-thalamic networks, whereas spindles are of thalamic origin. ${ }^{128,129}$

Given that SWD mechanisms remain elusive, animal models are still crucial for investigating absence seizures. Indeed, invasive recordings or excised tissues are hardly accessible from patients, as they cannot be surgically treated. The fact that acute insults are not major precipitators of absence seizures, together with their strong hereditary component, makes genetic models the most relevant tools for experimental research. Mouse models include the lethargic, tottering, leaner, and stargazer phenotypes, ${ }^{130}$ whereas the main rat models are called Genetic Absence Epilepsy in Rats from Strasbourg (GAERS) and WAG/ Rij. ${ }^{131}$ Mouse models of absence epilepsy have monogenic mutations affecting voltage-gated $\mathrm{Ca}^{2+}$ channels. In the soma of thalamic relays, T-type $\mathrm{Ca}^{2+}$ currents normally generate the burst firing that entrains thalamocortical networks into slow oscillations, primarily during non-rapid-eyemovement sleep. ${ }^{132}$ In mutant mice, those burst generators are more likely to engage neocortical pyramidal, dorsal thalamic, and GABAergic reticular thalamic neurons into aberrant SWD-like synchronization events. ${ }^{130}$ Moreover, net inhibition of thalamic relays, a situation that normally activates T-type $\mathrm{Ca}^{2+}$ currents, seems to be increased in tottering and lethargic mice. In this case, presynaptic P/Q-type $\mathrm{Ca}^{2+}$ channels on inputs to thalamocortical cells might be involved instead. ${ }^{130}$

Mutation of P/Q-type $\mathrm{Ca}^{2+}$ channels brings a disadvantage to mouse models: alterations in neurotransmitter release induce collateral defects such as cerebellar ataxia. Another drawback of mouse models is that they offer monogenic mutations, whereas the inheritance of absence epilepsy among humans is believed to combine multiple genetic anomalies. ${ }^{127}$ That is why the presumptively polygenic rat models GAERS and WAG/Rij are known to better simulate the human idiopathic epilepsies. ${ }^{133,134}$ Similar to mouse models, both GAERS and WAG/Rij show higher expression and function of T-type $\mathrm{Ca}^{2+}$ channels, reinforcing the idea that exaggerated burst firing in the dorsal thalamus contribute to absence seizures. ${ }^{127}$ However, GAERS and WAG/Rij mutations are much more diverse, being age-dependent and/or region-specific. Those include a subtle reduction of D1 and D2 receptor densities in accumbal and striatal subregions, reduction of glutamate transporters on neocortical glia and neurons, increased expression of $\alpha$-amino-3-hydroxy-5methyl-4-isoxazolepropionic acid subunits in the neocortex, and increased tonic $\gamma$-aminobutyric acid-ergic transmission on thalamocortical cells. ${ }^{127,129}$ The complex profile of disturbances is also accompanied by subtle morphometric changes, the documentation of which is now increasing. A diffusion tensor imaging study showed that either myelination or fiber density in the corpus callosum are decreased to the extent that absence seizures recur in GAERS and WAG/Rij. ${ }^{135}$ This suggests that structural modifications do result from absence seizures, indicating that advanced brain imaging will provide new ways to clinically monitor the idiopathic epilepsies.

The high complexity of GAERS and WAG/Rij models could represent a disadvantage; that is, difficult interpretation of a diverse (and not fully known) genetic scenario. Nevertheless, both strains respond to drugs used to treat epileptic patients, ${ }^{134}$ supporting their face validity. Furthermore, SWD generalization in rats is similar to what was observed from the cat penicillin model, ${ }^{136}$ in addition to being consistent with a human study that found phase locking between deep thalamic paroxysms and SWD from the scalp EEG. ${ }^{137}$ By considering the contribution of genetic models, specialized authors conclude that cortex and thalamus are equally important in SWD generation, ${ }^{133}$ although limbic structures contribute to that as well. ${ }^{125}$ 

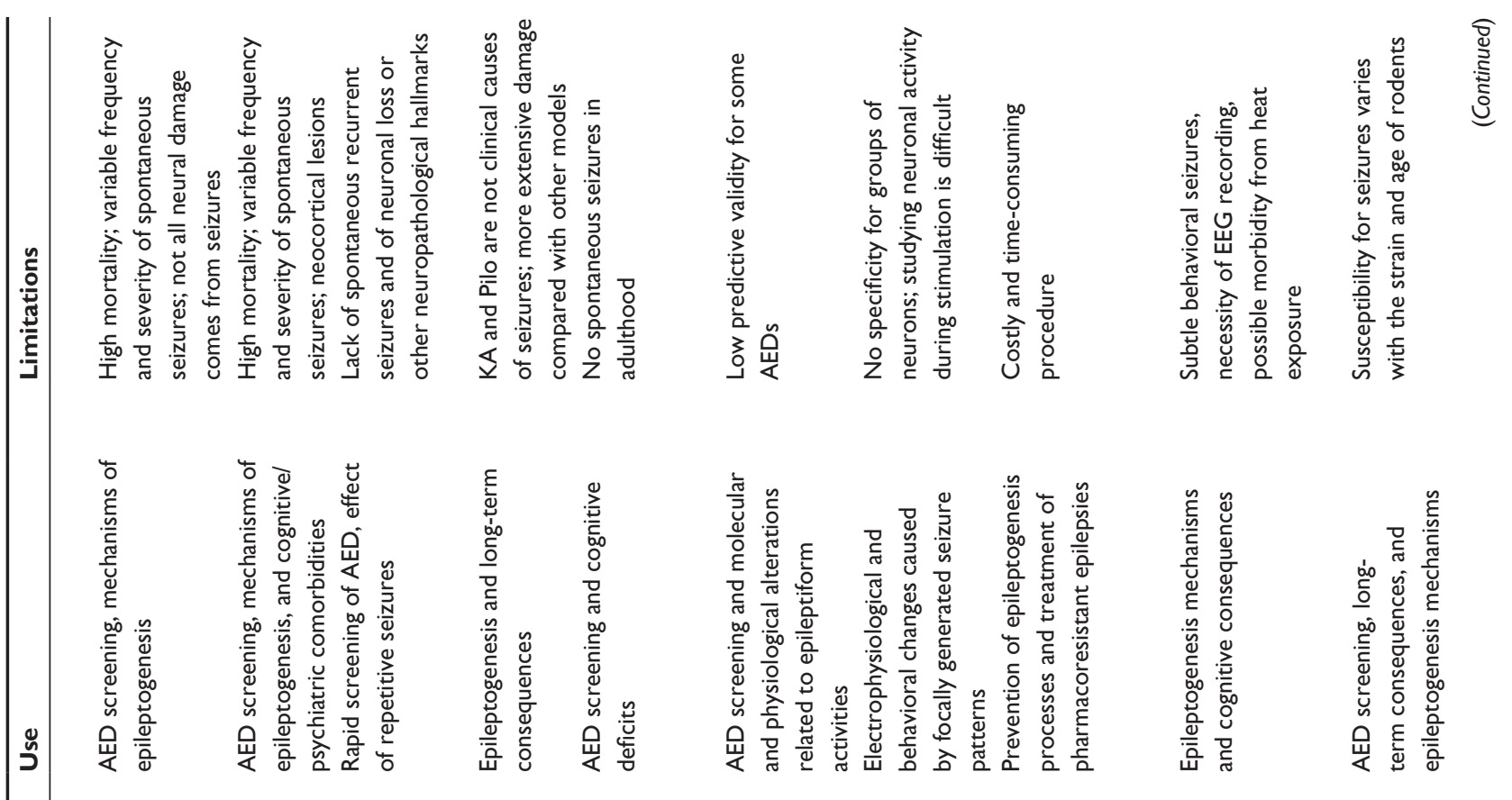

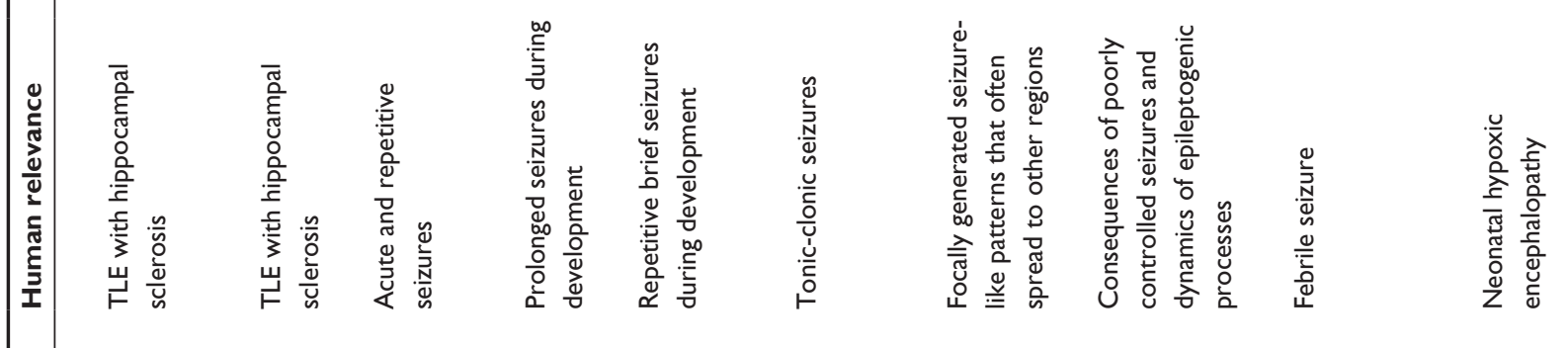
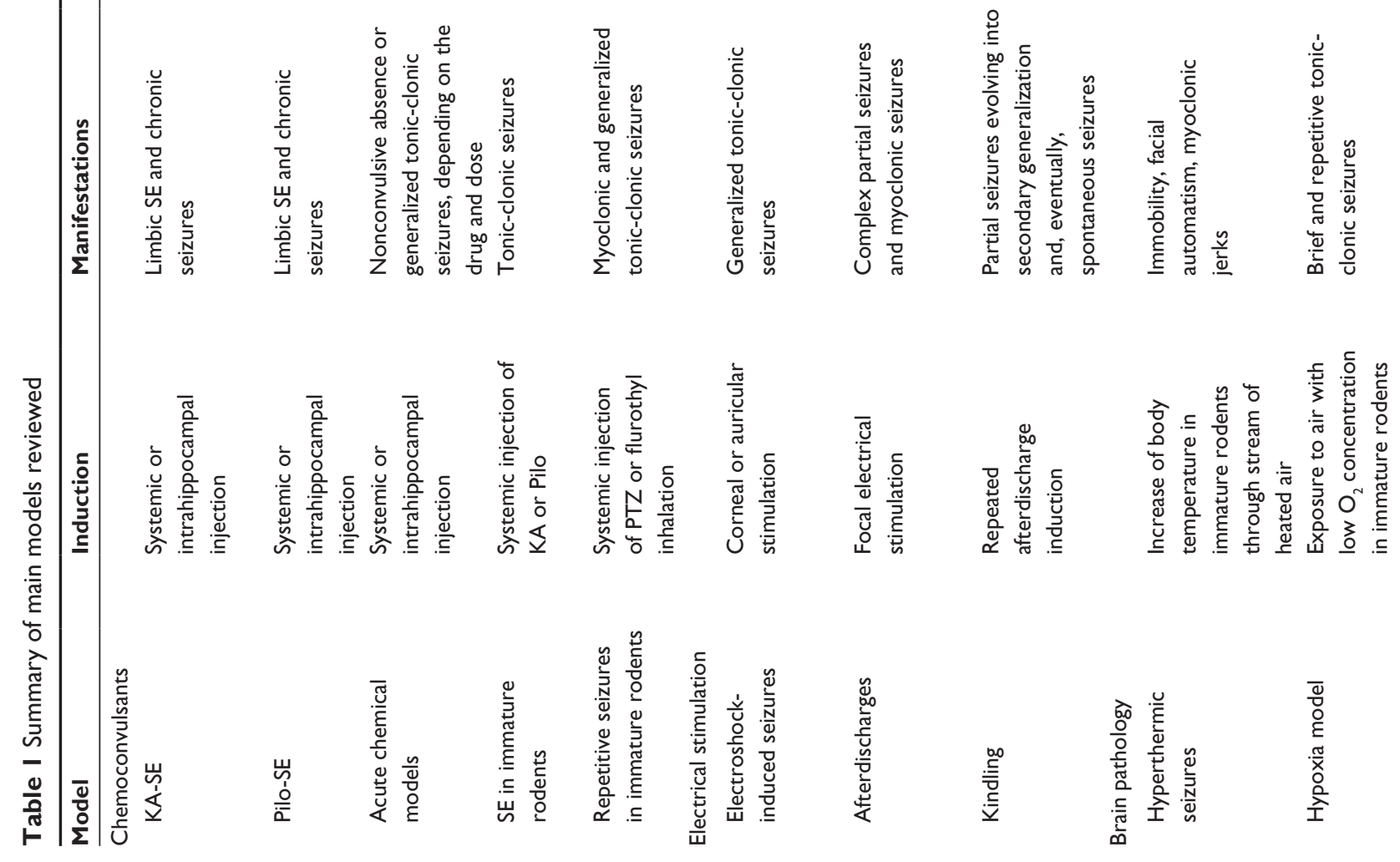


\section{Conclusion}

Animal models of epilepsy include several tools, including neurochemical agents, electrical stimulation protocols, thermal or hypoxic insults, traumatic injuries, optogenetics, and rodent strains with idiopathic or audiogenic-induced seizures. Important features, uses, and limitations of the models reviewed here are summarized in Table 1.

Chemoconvulsants allow for rapid investigation of epileptogenic mechanisms and AED screening at the expense of high mortality of subjects and high variability in the frequency and severity of spontaneous seizures. Electrical stimulation protocols are less harmful to subjects and offer better control of seizures, but electrophysiological procedures can be costly and time-consuming. Nonchemical and nonelectrical insults might approximate clinical conditions of developmental epilepsies, but inconsistencies in seizure susceptibility depending on experimental procedures hamper comparisons between rodents and humans. Finally, seizure-prone strains eliminate much of the artificiality of experimentally induced seizures, but their genetic alterations are not fully known, not to mention that sensorial triggers are still needed to induce seizures in strains such as WARs. Such a number of experimental options probably reflect the diversity of seizure types in humans. Even focal syndromes yield brain-wide alterations, thereby precipitating cognitive and psychiatric disturbances. The quest for seizure mechanisms can additionally provide insights into overall brain functions and consciousness, and animal models will continue to promote the progress of both epilepsy and neurophysiology research.

\section{Acknowledgments}

This work was supported by the Sao Paulo Research Foundation (CInAPCe project 05/56447-7, to JPL), the National Council for Scientific and Technological Development, and the Coordination for the Improvement of Higher Education Personnel (project A034_2013, to LK) in Brazil.

\section{Disclosure}

The authors declare that they have no conflict of interest.

\section{References}

1. Bertram EH. Temporal lobe epilepsy: where do the seizures really begin? Epilepsy Behav. 2009;14(suppl 1):32-37.

2. Kandratavicius L, Rosa-Neto P, Monteiro MR, et al. Distinct increased metabotropic glutamate receptor type 5 (mGluR5) in temporal lobe epilepsy with and without hippocampal sclerosis. Hippocampus. 2013; 23(12):1212-1230

3. Leite JP, Garcia-Cairasco N, Cavalheiro EA. New insights from the use of pilocarpine and kainate models. Epilepsy Res. 2002;50(1-2):93-103. 
4. Mathern GW, Adelson PD, Cahan LD, Leite JP. Hippocampal neuron damage in human epilepsy: Meyer's hypothesis revisited. Prog Brain Res. 2002;135:237-251.

5. Lothman EW, Bertram EH III. Epileptogenic effects of status epilepticus. Epilepsia. 1993;34(s1)(suppl 1):S59-S70.

6. Sharma AK, Reams RY, Jordan WH, Miller MA, Thacker HL, Snyder PW. Mesial temporal lobe epilepsy: pathogenesis, induced rodent models and lesions. Toxicol Pathol. 2007;35(7):984-999.

7. Nadler JV, Perry BW, Cotman CW. Intraventricular kainic acid preferentially destroys hippocampal pyramidal cells. Nature. 1978; 271(5646):676-677.

8. Raedt R, Van Dycke A, Van Melkebeke D, et al. Seizures in the intrahippocampal kainic acid epilepsy model: characterization using long-term video-EEG monitoring in the rat. Acta Neurol Scand. 2009; 119(5):293-303.

9. Bonilha L, Elm JJ, Edwards JC, et al. How common is brain atrophy in patients with medial temporal lobe epilepsy? Epilepsia. 2010; 51(9):1774-1779.

10. Furtado MA, Braga GK, Oliveira JA, Del Vecchio F, Garcia-Cairasco N. Behavioral, morphologic, and electroencephalographic evaluation of seizures induced by intrahippocampal microinjection of pilocarpine. Epilepsia. 2002;43(suppl 5):37-39.

11. Turski WA, Cavalheiro EA, Schwarz M, Czuczwar SJ, Kleinrok Z, Turski L. Limbic seizures produced by pilocarpine in rats: behavioural, electroencephalographic and neuropathological study. Behav Brain Res. 1983;9(3):315-335.

12. Cavalheiro EA, Leite JP, Bortolotto ZA, Turski WA, Ikonomidou C, Turski L. Long-term effects of pilocarpine in rats: structural damage of the brain triggers kindling and spontaneous recurrent seizures. Epilepsia. 1991;32(6):778-782.

13. Leite JP, Cavalheiro EA. Effects of conventional antiepileptic drugs in a model of spontaneous recurrent seizures in rats. Epilepsy Res. 1995; 20(2):93-104.

14. Wozny C, Kivi A, Lehmann TN, Dehnicke C, Heinemann U, Behr J. Comment on "On the origin of interictal activity in human temporal lobe epilepsy in vitro". Science. 2003;301(5632):463.

15. Knopp A, Kivi A, Wozny C, Heinemann U, Behr J. Cellular and network properties of the subiculum in the pilocarpine model of temporal lobe epilepsy. J Comp Neurol. 2005;483(4):476-488.

16. Kandratavicius L, Monteiro MR, Assirati JA Jr, Carlotti CG Jr, Hallak JE, Leite JP. Neurotrophins in mesial temporal lobe epilepsy with and without psychiatric comorbidities. J Neuropathol Exp Neurol. 2013; 72(11):1029-1042.

17. Mudò G, Jiang XH, Timmusk T, Bindoni M, Belluardo N. Change in neurotrophins and their receptor mRNAs in the rat forebrain after status epilepticus induced by pilocarpine. Epilepsia. 1996;37(2):198-207.

18. Kandratavicius L, Monteiro MR, Hallak JE, Carlotti CG Jr, Assirati JA Jr, Leite JP. Microtubule-associated proteins in mesial temporal lobe epilepsy with and without psychiatric comorbidities and their relation with granular cell layer dispersion. Biomed Res Int. 2013; 2013:960126

19. Pauli E, Hildebrandt M, Romstöck J, Stefan H, Blümcke I. Deficient memory acquisition in temporal lobe epilepsy is predicted by hippocampal granule cell loss. Neurology. 2006;67(8):1383-1389.

20. Leite JP, Nakamura EM, Lemos T, Masur J, Cavalheiro EA. Learning impairment in chronic epileptic rats following pilocarpine-induced status epilepticus. Braz J Med Biol Res. 1990;23(8):681-683.

21. Faure JB, Marques-Carneiro JE, Akimana G, et al. Attention and executive functions in a rat model of chronic epilepsy. Epilepsia. 2014; 55(5):644-653.

22. Barkmeier DT, Loeb JA. An animal model to study the clinical significance of interictal spiking. Clin EEG Neurosci. 2009;40(4):234-238.

23. Ni H, Li C, Tao LY, Cen JN. Physical exercise improves learning by modulating hippocampal mossy fiber sprouting and related gene expression in a developmental rat model of penicillin-induced recurrent epilepticus. Toxicol Lett. 2009;191(1):26-32.
24. Garcia-Cairasco N, Moyses-Neto M, Del Vecchio F, et al. Elucidating the neurotoxicity of the star fruit. Angew Chem Int Ed Engl. 2013; 52(49):13067-13070.

25. Löscher W. Animal models of intractable epilepsy. Prog Neurobiol. 1997;53(2):239-258.

26. Löscher W. Critical review of current animal models of seizures and epilepsy used in the discovery and development of new antiepileptic drugs. Seizure. 2011;20(5):359-368.

27. Löscher W. Animal models of epilepsy for the development of antiepileptogenic and disease-modifying drugs. A comparison of the pharmacology of kindling and post-status epilepticus models of temporal lobe epilepsy. Epilepsy Res. 2002;50(1-2):105-123.

28. Shinnar S, Pellock JM, Moshé SL, et al. In whom does status epilepticus occur: age-related differences in children. Epilepsia. 1997;38(8): 907-914.

29. Raspall-Chaure M, Chin RF, Neville BG, Scott RC. Outcome of paediatric convulsive status epilepticus: a systematic review. Lancet Neurol. 2006;5(9):769-779.

30. Kubová H, Mareš P, Suchomelová L, Brozek G, Druga R, Pitkänen A. Status epilepticus in immature rats leads to behavioural and cognitive impairment and epileptogenesis. Eur J Neurosci. 2004;19(12): 3255-3265.

31. Hirsch E, Baram TZ, Snead OC III. Ontogenic study of lithium-pilocarpine-induced status epilepticus in rats. Brain Res. 1992;583(1-2): 120-126.

32. Pitkänen A, Schwartzkroin PA, Moshé SL. Models of seizures and epilepsy. Amsterdam: Elsevier Academic; 2006.

33. Leite JP, Babb TL, Pretorius JK, Kuhlman PA, Yeoman KM, Mathern GW. Neuron loss, mossy fiber sprouting, and interictal spikes after intrahippocampal kainate in developing rats. Epilepsy Res. 1996; 26(1):219-231.

34. Cross DJ, Cavazos JE. Synaptic reorganization in subiculum and CA3 after early-life status epilepticus in the kainic acid rat model. Epilepsy Res. 2007;73(2):156-165.

35. Cilio MR, Sogawa Y, Cha BH, Liu X, Huang LT, Holmes GL. Longterm effects of status epilepticus in the immature brain are specific for age and model. Epilepsia. 2003;44(4):518-528.

36. Kubová H, Druga R, Lukasiuk K, et al. Status epilepticus causes necrotic damage in the mediodorsal nucleus of the thalamus in immature rats. J Neurosci. 2001;21(10):3593-3599.

37. Sankar R, Shin DH, Liu H, Mazarati A, Pereira de Vasconcelos A, Wasterlain CG. Patterns of status epilepticus-induced neuronal injury during development and long-term consequences. J Neurosci. 1998; 18(20):8382-8393.

38. Kubová $\mathrm{H}$, Mareš $\mathrm{P}$. Are morphologic and functional consequences of status epilepticus in infant rats progressive? Neuroscience. 2013; 235:232-249.

39. Huang L, Cilio MR, Silveira DC, et al. Long-term effects of neonatal seizures: a behavioral, electrophysiological, and histological study. Brain Res Dev Brain Res. 1999;118(1-2):99-107.

40. Holmes GL, Sarkisian M, Ben-Ari Y, Chevassus-Au-Louis N. Mossy fiber sprouting after recurrent seizures during early development in rats. J Comp Neurol. 1999;404(4):537-553.

41. Weller A, Mostofsky DI. Ontogenetic development and pentylenetetrazol seizure thresholds in rats. Physiol Behav. 1995;57(4):629-631.

42. Holmes GL, Gairsa JL, Chevassus-Au-Louis N, Ben-Ari Y. Consequences of neonatal seizures in the rat: morphological and behavioral effects. Ann Neurol. 1998;44(6):845-857.

43. Liu Z, Yang Y, Silveira DC, et al. Consequences of recurrent seizures during early brain development. Neuroscience. 1999;92(4):1443-1454.

44. Riviello P, de Rogalski Landrot I, Holmes GL. Lack of cell loss following recurrent neonatal seizures. Brain Res Dev Brain Res. 2002; 135(1-2):101-104.

45. Hernan AE, Holmes GL, Isaev D, Scott RC, Isaeva E. Altered short-term plasticity in the prefrontal cortex after early life seizures. Neurobiol Dis. 2013;50:120-126. 
46. Kleen JK, Sesqué A, Wu EX, et al. Early-life seizures produce lasting alterations in the structure and function of the prefrontal cortex. Epilepsy Behav. 2011;22(2):214-219.

47. Löscher W, Schmidt D. Which animal models should be used in the search for new antiepileptic drugs? A proposal based on experimental and clinical considerations. Epilepsy Res. 1988;2(3):145-181.

48. Frankel WN, Taylor L, Beyer B, Tempel BL, White HS. Electroconvulsive thresholds of inbred mouse strains. Genomics. 2001; 74(3):306-312.

49. Browning RA, Nelson DK. Variation in threshold and pattern of electroshock-induced seizures in rats depending on site of stimulation. Life Sci. 1985;37(23):2205-2211.

50. Epps SA, Weinshenker D. Rhythm and blues: animal models of epilepsy and depression comorbidity. Biochem Pharmacol. 2013; 85(2):135-146.

51. Tsankova NM, Kumar A, Nestler EJ. Histone modifications at gene promoter regions in rat hippocampus after acute and chronic electroconvulsive seizures. J Neurosci. 2004;24(24):5603-5610.

52. Calais JB, Valvassori SS, Resende WR, et al. Long-term decrease in immediate early gene expression after electroconvulsive seizures. J Neural Transm. 2013;120(2):259-266.

53. Sloan DM, Zhang D, Bertram EH III. Increased GABAergic inhibition in the midline thalamus affects signaling and seizure spread in the hippocampus-prefrontal cortex pathway. Epilepsia. 2011;52(3): 523-530.

54. Velísek L, Mareš P. Hippocampal afterdischarges in rats. I. Effects of antiepileptics. Physiol Res. 2004;53(4):453-461.

55. Ma J, Leung LS. Kindled seizure in the prefrontal cortex activated behavioral hyperactivity and increase in accumbens gamma oscillations through the hippocampus. Behav Brain Res. 2010;206(1):68-77.

56. Kotloski R, Lynch M, Lauersdorf S, Sutula T. Repeated brief seizures induce progressive hippocampal neuron loss and memory deficits. Prog Brain Res. 2002;135:95-110.

57. Norwood BA, Bumanglag AV, Osculati F, et al. Classic hippocampal sclerosis and hippocampal-onset epilepsy produced by a single "cryptic" episode of focal hippocampal excitation in awake rats. J Comp Neurol. 2010;518(16):3381-3407.

58. Bragin A, Penttonen M, Buzsáki G. Termination of epileptic afterdischarge in the hippocampus. J Neurosci. 1997;17(7):2567-2579.

59. Ma J, Leung LW. Medial septum mediates the increase in post-ictal behaviors and hippocampal gamma waves after an electrically induced seizure. Brain Res. 1999;833(1):51-57.

60. Leung LS, Ma J, McLachlan RS. Behaviors induced or disrupted by complex partial seizures. Neurosci Biobehav Rev. 2000;24(7):763-775.

61. Ma J, Brudzynski SM, Leung LW. Involvement of the nucleus accumbens-ventral pallidal pathway in postictal behavior induced by a hippocampal afterdischarge in rats. Brain Res. 1996;739(1-2):26-35.

62. Ma J, Brudzynski SM, Leung LW. A role of subicular and hippocampa afterdischarges in initiation of locomotor activity in rats. Brain Res. 1998;793(1-2):112-118.

63. Osawa S, Iwasaki M, Hosaka R, et al. Optogenetically induced seizure and the longitudinal hippocampal network dynamics. PLoS ONE. 2013;8(4):e60928.

64. Deisseroth K. Optogenetics. Nat Methods. 2011;8(1):26-29.

65. Goddard GV, McIntyre DC, Leech CK. A permanent change in brain function resulting from daily electrical stimulation. Exp Neurol. 1969; 25(3):295-330.

66. Racine RJ. Modification of seizure activity by electrical stimulation. I. After-discharge threshold. Electroencephalogr Clin Neurophysiol. 1972;32(3):269-279.

67. Racine RJ. Modification of seizure activity by electrical stimulation. II. Motor seizure. Electroencephalogr Clin Neurophysiol. 1972;32(3): 281-294.

68. Sayin U, Osting S, Hagen J, Rutecki P, Sutula T. Spontaneous seizures and loss of axo-axonic and axo-somatic inhibition induced by repeated brief seizures in kindled rats. J Neurosci. 2003;23(7):2759-2768.
69. Sloviter RS, Zappone CA, Bumanglag AV, Norwood BA, Kudrimoti H. On the relevance of prolonged convulsive status epilepticus in animals to the etiology and neurobiology of human temporal lobe epilepsy. Epilepsia. 2007;48(s8)(suppl 8):6-10.

70. Sutula TP. Mechanisms of epilepsy progression: current theories and perspectives from neuroplasticity in adulthood and development. Epilepsy Res. 2004;60(2-3):161-171.

71. He XP, Wen R, McNamara JO. Impairment of kindling development in phospholipase C $\gamma 1$ heterozygous mice. Epilepsia. 2014;55(3):456- 463.

72. Avanzini G, Depaulis A, Tassinari A, de Curtis M. Do seizures and epileptic activity worsen epilepsy and deteriorate cognitive function? Epilepsia. 2013;54(suppl 8):14-21.

73. Srivastava AK, Alex AB, Wilcox KS, White HS. Rapid loss of efficacy to the antiseizure drugs lamotrigine and carbamazepine: a novel experimental model of pharmacoresistant epilepsy. Epilepsia. 2013;54(7): 1186-1194.

74. Kotloski R, McNamara JO. Reduction of TrkB expression de novo in the adult mouse impairs epileptogenesis in the kindling model. Hippocampus. 2010;20(6):713-723.

75. Kandratavicius L, Hallak J, Carlotti C, Assirati J, Leite J. Neurotrophin receptors expression in mesial temporal lobe epilepsy with and without psychiatric comorbidities and their relation with seizure type and surgical outcome. Acta Neuropathol Commun. 2014;2(1):81.

76. Holmes GL. The long-term effects of neonatal seizures. Clin Perinatol. 2009;36(4):901-914, vii-viii.

77. Rakhade SN, Jensen FE. Epileptogenesis in the immature brain: emerging mechanisms. Nat Rev Neurol. 2009;5(7):380-391.

78. Baumann RJ, Duffner PK; American Academy of Pediatrics. Treatment of children with simple febrile seizures: the AAP practice parameter. Pediatr Neurol. 2000;23(1):11-17.

79. Dubé CM, McClelland S, Choy MK, et al. Fever, febrile seizures and epileptogenesis. In: Noebels JL, Avoli M, Rogawski MA, et al, eds. Jasper's Basic Mechanisms of the Epilepsies. Bethesda, MD: National Center for Biotechnology Information; 2012.

80. French JA, Williamson PD, Thadani VM, et al. Characteristics of medial temporal lobe epilepsy: I. Results of history and physical examination. Ann Neurol. 1993;34(6):774-780.

81. Kasperaviciute D, Catarino CB, Matarin M, et al; UK Brain Expression Consortium. Epilepsy, hippocampal sclerosis and febrile seizures linked by common genetic variation around SCN1A. Brain. 2013;136(Pt 10): 3140-3150.

82. Schuchmann S, Schmitz D, Rivera C, et al. Experimental febrile seizures are precipitated by a hyperthermia-induced respiratory alkalosis. Nat Med. 2006;12(7):817-823.

83. Dube C, Chen K, Eghbal-Ahmadi M, Brunson K, Soltesz I, Baram TZ. Prolonged febrile seizures in the immature rat model enhance hippocampal excitability long term. Ann Neurol. 2000;47(3):336-344.

84. Dubé CM, Ravizza T, Hamamura M, et al. Epileptogenesis provoked by prolonged experimental febrile seizures: mechanisms and biomarkers J Neurosci. 2010;30(22):7484-7494.

85. Notenboom RG, Ramakers GM, Kamal A, SpruijtBM, de Graan PN. Longlasting modulation of synaptic plasticity in rat hippocampus after earlylife complex febrile seizures. Eur J Neurosci. 2010;32(5):749-758.

86. Toth Z, Yan XX, Haftoglou S, Ribak CE, Baram TZ. Seizure-induced neuronal injury: vulnerability to febrile seizures in an immature rat model. J Neurosci. 1998;18(11):4285-4294.

87. Aicardi J, Chevrie JJ. Convulsive status epilepticus in infants and children. A study of 239 cases. Epilepsia. 1970;11(2):187-197.

88. White HS. Animal models of epileptogenesis. Neurology. 2002;59(9) (suppl 5):S7-S14.

89. Jensen FE, Applegate CD, Holtzman D, Belin TR, Burchfiel JL. Epileptogenic effect of hypoxia in the immature rodent brain. Ann Neurol. 1991;29(6):629-637.

90. Jensen FE, Blume H, Alvarado S, Firkusny I, Geary C. NBQX blocks acute and late epileptogenic effects of perinatal hypoxia. Epilepsia. 1995;36(10):966-972. 
91. Rakhade SN, Klein PM, Huynh T, et al. Development of later life spontaneous seizures in a rodent model of hypoxia-induced neonatal seizures. Epilepsia. 2011;52(4):753-765.

92. Talos DM, Sun H, Zhou X, et al. The interaction between early life epilepsy and autistic-like behavioral consequences: a role for the mammalian target of rapamycin (mTOR) pathway. PLoS ONE. 2012; 7(5):e35885.

93. Sanchez RM, Jensen FE. Maturational aspects of epilepsy mechanisms and consequences for the immature brain. Epilepsia. 2001; 42(5):577-585.

94. Jensen FE, Wang C, Stafstrom CE, Liu Z, Geary C, Stevens MC. Acute and chronic increases in excitability in rat hippocampal slices after perinatal hypoxia In vivo. J Neurophysiol. 1998;79(1):73-81.

95. Pitkänen A, McIntosh TK. Animal models of post-traumatic epilepsy. $J$ Neurotrauma. 2006;23(2):241-261.

96. Pitkänen A, Immonen RJ, Gröhn $\mathrm{OH}$, Kharatishvili I. From traumatic brain injury to posttraumatic epilepsy: what animal models tell us about the process and treatment options. Epilepsia. 2009;50(suppl 2):21-29.

97. D’Ambrosio R, Fairbanks JP, Fender JS, Born DE, Doyle DL, Miller JW. Post-traumatic epilepsy following fluid percussion injury in the rat. Brain. 2004;127(Pt 2):304-314.

98. Kharatishvili I, Nissinen JP, McIntosh TK, Pitkänen A. A model of posttraumatic epilepsy induced by lateral fluid-percussion brain injury in rats. Neuroscience. 2006;140(2):685-697.

99. D'Ambrosio R, Fender JS, Fairbanks JP, et al. Progression from frontal-parietal to mesial-temporal epilepsy after fluid percussion injury in the rat. Brain. 2005;128(Pt 1):174-188.

100. Shultz SR, Cardamone L, Liu YR, et al. Can structural or functional changes following traumatic brain injury in the rat predict epileptic outcome? Epilepsia. 2013;54(7):1240-1250.

101. Kharatishvili I, Pitkänen A. Posttraumatic epilepsy. Curr Opin Neurol. 2010;23(2):183-188.

102. Hesdorffer DC, Hauser WA, Annegers JF, Cascino G. Major depression is a risk factor for seizures in older adults. Ann Neurol. 2000; 47(2):246-249

103. Garcia-Cairasco N. A critical review on the participation of inferior colliculus in acoustic-motor and acoustic-limbic networks involved in the expression of acute and kindled audiogenic seizures. Hear Res. 2002;168(1-2):208-222.

104. Garcia-Cairasco N, Terra VC, Doretto MC. Midbrain substrates of audiogenic seizures in rats. Behav Brain Res. 1993;58(1-2):57-67.

105. Ross KC, Coleman JR. Developmental and genetic audiogenic seizure models: behavior and biological substrates. Neurosci Biobehav Rev. 2000;24(6):639-653.

106. Krushinsky VL. News in investigations of experimental epilepsy. Usp Sovrem Biol. 1949;28:108-133.

107. Jobe PC, Picchioni AL, Chin L. Role of brain norepinephrine in audiogenic seizure in the rat. J Pharmacol Exp Ther. 1973;184(1):1-10.

108. Zhao DY, Wu XR, Pei YQ, Zuo QH. Kindling phenomenon of hyperthermic seizures in the epilepsy-prone versus the epilepsy-resistant rat. Brain Res. 1985;358(1-2):390-393.

109. van Luijtelaar EL, Coenen AM. Two types of electrocortical paroxysms in an inbred strain of rats. Neurosci Lett. 1986;70(3):393-397.

110. Marescaux C, Vergnes M, Kiesmann M, Depaulis A, Micheletti G, Warter JM. Kindling of audiogenic seizures in Wistar rats: an EEG study. Exp Neurol. 1987;97(1):160-168.

111. Doretto MC, Fonseca CG, Lôbo RB, Terra VC, Oliveira JA, Garcia-Cairasco N. Quantitative study of the response to genetic selection of the Wistar audiogenic rat strain (WAR). Behav Genet. 2003;33(1):33-42.

112. Kiesmann M, Marescaux C, Vergnes M, Micheletti G, Depaulis A, Warter JM. Audiogenic seizures in Wistar rats before and after repeated auditory stimuli: clinical, pharmacological, and electroencephalographic studies. J Neural Transm. 1988;72(3):235-244.
113. Dutra Moraes MF, Galvis-Alonso OY, Garcia-Cairasco N. Audiogenic kindling in the Wistar rat: a potential model for recruitment of limbic structures. Epilepsy Res. 2000;39(3):251-259.

114. Romcy-Pereira RN, Garcia-Cairasco N. Hippocampal cell proliferation and epileptogenesis after audiogenic kindling are not accompanied by mossy fiber sprouting or Fluoro-Jade staining. Neuroscience. 2003; 119(2):533-546.

115. Galvis-Alonso OY, Cortes De Oliveira JA, Garcia-Cairasco N. Limbic epileptogenicity, cell loss and axonal reorganization induced by audiogenic and amygdala kindling in wistar audiogenic rats (WAR strain). Neuroscience. 2004;125(3):787-802.

116. Coenen AM, Van Luijtelaar EL. The WAG/Rij rat model for absence epilepsy: age and sex factors. Epilepsy Res. 1987;1(5):297-301.

117. Sarkisova K, van Luijtelaar G. The WAG/Rij strain: a genetic animal model of absence epilepsy with comorbidity of depression [corrected]. Prog Neuropsychopharmacol Biol Psychiatry. 2011; 35(4):854-876.

118. Kandratavicius L, Ruggiero RN, Hallak JE, Garcia-Cairasco N, Leite JP. Pathophysiology of mood disorders in temporal lobe epilepsy. Rev Bras Psiquiatr. 2012;34(supp1 2):S233-S245.

119. Pineda E, Shin D, Sankar R, Mazarati AM. Comorbidity between epilepsy and depression: experimental evidence for the involvement of serotonergic, glucocorticoid, and neuroinflammatory mechanisms. Epilepsia. 2010;51(suppl 3):110-114.

120. Garcia-Cairasco N, Oliveira JA, WakamatsuH, Bueno ST, Guimarães FS. Reduced exploratory activity of audiogenic seizures susceptible Wistar rats. Physiol Behav. 1998;64(5):671-674.

121. Umeoka EH, Garcia SB, Antunes-Rodrigues J, Elias LL, Garcia-Cairasco N. Functional characterization of the hypothalamicpituitary-adrenal axis of the Wistar Audiogenic Rat (WAR) strain. Brain Res. 2011;1381:141-147.

122. Fazan R Jr, de Oliveira M, Oliveira JA, Salgado HC, Garcia-Cairasco N. Changes in autonomic control of the cardiovascular system in the Wistar audiogenic rat (WAR) strain. Epilepsy Behav. 2011;22(4): 666-670.

123. Jallon P, Latour P. Epidemiology of idiopathic generalized epilepsies. Epilepsia. 2005;46(s9)(suppl 9):10-14.

124. Hughes JR. Absence seizures: a review of recent reports with new concepts. Epilepsy Behav. 2009;15(4):404-412.

125. Onat FY, van Luijtelaar G, Nehlig A, Snead OC III. The involvement of limbic structures in typical and atypical absence epilepsy. Epilepsy Res. 2013;103(2-3):111-123.

126. Bayne T. The presence of consciousness in absence seizures. Behav Neurol. 2011;24(1):47-53.

127. Jones NC, O’Brien TJ, Powell KL. Morphometric changes and molecular mechanisms in rat models of idiopathic generalized epilepsy with absence seizures. Neurosci Lett. 2011;497(3):185-193.

128. Leresche N, Lambert RC, Errington AC, Crunelli V. From sleep spindles of natural sleep to spike and wave discharges of typical absence seizures: is the hypothesis still valid? Pflugers Arch. 2012;463(1):201-212.

129. Crunelli V, Cope DW, Terry JR. Transition to absence seizures and the role of GABA(A) receptors. Epilepsy Res. 2011;97(3): 283-289.

130. Felix R. Insights from mouse models of absence epilepsy into $\mathrm{Ca}^{2+}$ channel physiology and disease etiology. Cell Mol Neurobiol. 2002; 22(2):103-120.

131. Akman O, Demiralp T, Ates N, Onat FY. Electroencephalographic differences between WAG/Rij and GAERS rat models of absence epilepsy. Epilepsy Res. 2010;89(2-3):185-193.

132. Llinás RR, Steriade M. Bursting of thalamic neurons and states of vigilance. J Neurophysiol. 2006;95(6):3297-3308.

133. Avoli M. A brief history on the oscillating roles of thalamus and cortex in absence seizures. Epilepsia. 2012;53(5):779-789. 
134. van Luijtelaar EL, Drinkenburg WH, van Rijn CM, Coenen AM. Rat models of genetic absence epilepsy: what do EEG spike-wave discharges tell us about drug effects? Methods Find Exp Clin Pharmacol. 2002;24 Suppl D:65-70.

135. Chahboune H, Mishra AM, DeSalvo MN, et al. DTI abnormalities in anterior corpus callosum of rats with spike-wave epilepsy. Neuroimage. 2009;47(2):459-466.
136. Fisher RS, Prince DA. Spike-wave rhythms in cat cortex induced by parenteral penicillin. I. Electroencephalographic features. Electroencephalogr Clin Neurophysiol. 1977;42(5):608-624.

137. Williams D. A study of thalamic and cortical rhythms in petit mal. Brain. 1953;76(1):50-69.

Neuropsychiatric Disease and Treatment

\section{Publish your work in this journal}

Neuropsychiatric Disease and Treatment is an international, peerreviewed journal of clinical therapeutics and pharmacology focusing on concise rapid reporting of clinical or pre-clinical studies on a range of neuropsychiatric and neurological disorders. This journal is indexed on PubMed Central, the 'PsycINFO' database and CAS, and is the official journal of The International Neuropsychiatric Association (INA). The manuscript management system is completely online and includes a very quick and fair peer-review system, which is all easy to use. Visit http://www.dovepress.com/testimonials.php to read real quotes from published authors.

Submit your manuscript here: http://www.dovepress.com/neuropsychiatric-disease-and-treatment-journal 